\title{
Research on Standard System of Third-Party Governance on Environmental pollution
}

\author{
XU Bingsheng ${ }^{1, ~ a, ~ L I N ~ L i n g ~}{ }^{1, b}$, Huang Jin ${ }^{1, c}$, and WANG Hongtao ${ }^{2, d}$ \\ ${ }^{1}$ China National Institute of Standardization, Beijing 100191, China \\ 2 School of Environment, Tsinghua University, Beijing 100084, China

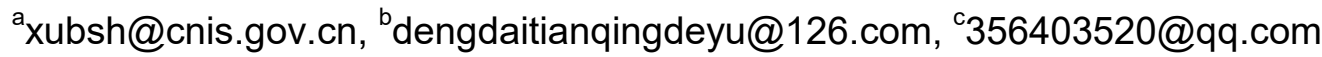

\begin{abstract}
Keywords: Environmental pollution; Third-party governance; Standard; Standard system
Abstract. Combined with the development of national and industrial standards on environmental pollution control, the paper puts an emphasis on building a scientific and reasonable standard system of third-party governance on environmental pollution based on the system theory and methodology of systems engineering. The standard system includes four subsystems that are further divided into 22 professional fields, which supplies a theoretical guidance for formulating related technical and service standards. By analyzing current standards, it is found that the formulation of packaged standards concerning on the performance evaluation of third-party governance on environmental pollution urgently needs to be done. The research results can reinforce the effect of pollution control and perfect the establishment of mechanism of third-party governance on environmental pollution. Furthermore, the construction of the standardization system has a guiding significance on leading environmental protection industry and promoting market-oriented development.
\end{abstract}

\section{Introduction}

With the rapid economic development in China, excessive resource consumption and environmental pollution become increasingly serious. The pollutant emissions remain large and pollution continues to become worse. However, slow progress is made in environmental control. Environmental protection and pollution control are confronted with new situations and challenges. On the one hand, the haze is affecting wider area, lasting for a longer period and causing more pollution and hazards. In 2014, among the exhaust gas emissions in China, sulfur dioxide was 19.744 million tons and nitric oxide 20.780 million tons and smog (dust) 17.408 million tons. In addition, the sewage discharge greatly exceeded the environmental capacity in China. In 2004, the total sewage discharge in China was 71.62 billion tons, among which, the industrial sewage was 20.53 billion tons and municipal domestic sewage 51.03 billion tons [1,2]. On the other hand, as significant improvements have been made in the overall national strength in recent years, the total investment into environmental pollution control has also experienced a noticeable increase. The total investment in 2014 reached CNY 957.55 billion, increased by $43.9 \%$ compared with that of 2010 . However, there are still some problems in the pollution control in China: the input-output efficiency remains low; the equipment for pollution control is not effectively allocated, and most of pollution dischargers are confronted with limited facilities or discontinuous running of facilities. As a result, the control results are far behind the expected achievements and fail to meet the requirements for up-to-standard discharge of pollutants [3].

A gradual consensus is that the third-party environmental pollution control (TEPC) shall be promoted to solve the problems in emission reduction and pollution control. TEPC is a new mode, under which the pollution dischargers make direct payment or pay in accordance with the contracts to entrust environmental services companies to control the pollution, indicating that the market operation mechanism of environmental control has shifted from "holding those who cause pollution responsible for cleaning up" to "holding those who cause pollution responsible for cleaning up + third party control" [3]. According to different pollution dischargers, the services can be classified into services at enterprise demand side and services at government demand side, including the fields of industrial pollution control and government procurement of public services. According to control 
methods, the services can be classified into entrusted operations and managed operations for pollution control. To carry out TEPC in key industries or in public fields can enhance a centralized and professional control of pollution and attract social capital into the transformation of pollution control technology as well as operation and management of pollution control projects, so as to give play to the technical advantages of pollution control enterprises, improve control efficiency and enhance control results $[4,5]$.

However, unreasonable assessment and poor mechanisms exist in TEPC. Currently, there is no scientific, reasonable and fair mechanism for performance assessment and evaluation, or relevant technical standards for measurement and verification of emission reduction in pollution control. Consequently, the results of pollution control projects cannot be objectively measured. Besides, due to lack of scientific basis for relevant supporting policies, a reasonable and effective TEPC mode has not been formed yet, resulting in unclear responsibilities of pollution dischargers and third party enterprises. This, in turn, has severely compromised the enthusiasm of demand enterprises to introduce TEPC. Additionally, lack of scientific and reasonable financing assessment standards, risk prevention mechanisms and payment mechanisms has brought troubles to the financing of pollution control projects undertaken by third party enterprises. These enterprises, hence, fail to ensure a reasonable and effective utilization of financial capital. As a result, the project revenue cannot be guaranteed, hindering large-scale and sound development of third-party pollution control enterprises $[6,7]$.

In light of issues of TEPC in China, including obstacles in responsibility transfer, tax, financing, economic risks, technologies and evaluation of control results, research on the TEPC-supported standard system and evaluation methods is the key to solve the above issues. Therefore, standardization study on third-party pollution control is urgently required to establish a standard system with reasonable structure, highlights and scientific feasibility, and to form a standardized and typical pattern for third party control. In this paper, based on the theory of standardization and situations of domestic and foreign TEPC-supported standard systems, a detailed analysis is made on the system environment of the TEPC industry in China. From the aspects of development and standardization of environmental protection industry in China, an introduction is given to the control and management of environmental protection as well as revisions of service standards in other countries or regions where environmental protection industry is relatively mature. Moreover, the scientificity and practicability of standard formulation are also considered as a whole, thus providing a theoretical reference for common technologies related to TEPC and standards on management and services.

\section{Research Method}

A TEPC-supported standard system shall be established on the principles of standardization and on the basis of systematical analysis and standardization supporting relationships to fully investigate the progresses on relevant research at home and aboard. The fields including public environmental facilities and industrial parks shall be focused on in order to deeply investigate the development trends of the economic, political, cultural, social, and ecological civilization construction in China and analyze the current and future focuses and situation changes. Based on the analysis on the current policies and the standard establishment related to environmental pollution control in China, the establishment of a standard system shall focus on general basics, requirements for emission and detection method, assessment of environmental control technology, engineering technology standards, environmental protection equipment and materials, environmental protection services and management and other fields, so as to use a list analysis method to select current standards, to determine the standards required for TEPC-supported standard system, and to lay a foundation for the establishment of such a TEPC-supported standard system.

The establishment of an ecological civilization standard system framework shall be guided by the above basic principles, and be based on standardization principles and systematical analysis, with 
correlations between targets and objects being considered. It is also necessary to integrate the classification methods of standard system framework which are commonly used in standardization fields at home and aboard. In this paper, the following methods are used to research and identify the ecological civilization standard system framework in China.

(1) Literature investigation

The literature investigation and data collection are combined to discuss relevant research progresses at home and aboard. Previous theoretical exploration and practical experience related to the ecological civilization construction in China are combined to deeply investigate the development trends of domestic spatial arrangement, urban-rural development and integration, green industry development, resource conservation and recycling, ecological environmental protection, ecological culture and supporting system implementation. With respect to the work of supporting the ecological civilization construction in China, a scientific and effective technology method has been formed to investigate relevant ecological civilization construction regulations, policies and standards and the development situations and to analyze relevant advanced international and foreign standards and materials, so as to fully know the current and future requirements for the ecological civilization standardization. Furthermore, the coverage of relevant laws and regulations is regarded as the main basis to determine the scope and boundaries of research on ecological civilization standard system.

(2) Theory of standardization

Ecological civilization construction is set as a standardization goal. A complete set of standards required for achieving the key tasks in ecological civilization standardization and performance assessment are planned and designed. The coverage and elements of system are determined. From the perspectives of scientific rationality, systematic comprehensiveness, coordinated matchability and advanced foreseeability of the standard system, coordination and optimization of standards shall be done by steps and stages to form a standard system which can guide the ecological civilization construction in China.

(3) Hierarchical analysis

A hierarchical analysis on the classified contents covered by ecological civilization system is conducted to reflect the subordination and inclusion relations among standard objects. The generality of the standard objects is reflected in higher-level standards and the individuality of those objects is reflected in lower-level standards. The standard demands and mutual supporting relations among standard functions are defined. Through management and research of the ecological civilization standards in relevant fields, dimension criterions are established, the key processes that need to be specified in the standard system are identified, so as to establish an ecological civilization standard system where national, industrial and local standards match each other.

\section{Sorting out of Standards Related with Environmental Pollution Control}

For the purpose of solving key problems which hamper the development of TEPC in China, including unclear responsibilities, lack of comprehensive assessment indexes and irregular third-party environmental protection industry services, the research on TEPC-supported standards and codes is imperative, and sorting out of key contents is an important basis for such research.

So far, there have been 2947 standards set by standardization institution at home and abroad. for environmental pollution control, which includes 565 Chinese national standards, 963 Chinese industry standards and 1419 international standards.

TEPC involves project construction and development, management and implementation, service and performance assessment. Cooperation mechanisms and legal liabilities of both parties need to be identified. However, Chinese standards for environmental pollution control are currently included in standard systems of environmental protection industry, pollution control technology, environmental monitoring and performance assessment, so there is not a unified standard system. Therefore, standards should be sorted out according to different purposes, different perspectives and different classification criteria. 
TEPC aims to assist enterprises in achieving emission reduction targets of factories and industrial parks in the whole life cycle of pollution control. Therefore, the standard system needs to involve many industries and fields and to cover aspects, such as environment, project construction, equipment manufacturing, monitoring and assessment.

Table 1 shows statistical results of standards set by different industries in the field of environmental pollution improvement. There are 354 standards in environmental protection industry, which occupies $23.2 \%$ of the total environmental protection and control standards. Meanwhile, 177 machinery industry standards and 78 chemical industry standards are set for supporting pollution control in each involved industry. Other industry standards account for less percentage as shown in Table 1.

Table 1 Quantity statistics of standards on environmental pollution improvement

\begin{tabular}{|c|c|c|c|c|}
\hline Number & Standard Category & Abbreviation & Amount & $\begin{array}{c}\text { Proportion of Total } \\
\text { Environmental Standards }\end{array}$ \\
\hline 1 & China National Standard & GB & 565 & $37.0 \%$ \\
\hline 2 & Environmental Industry & HJ & 354 & $23.2 \%$ \\
\hline 3 & Machinery Industry & JB & 177 & $11.6 \%$ \\
\hline 4 & Chemical Industry & HG & 78 & $5.1 \%$ \\
\hline 5 & Agricultural Industry & NY & 56 & $3.7 \%$ \\
\hline 6 & Power Industry & DL & 51 & $3.3 \%$ \\
\hline 7 & Construction Industry & CJ & 45 & $2.9 \%$ \\
\hline 8 & Construction Engineering Industry & CJJ & 36 & $2.4 \%$ \\
\hline 9 & Nuclear Industry & EJ & 18 & $1.2 \%$ \\
\hline 10 & Petrochemical Industry & SH & 14 & $0.9 \%$ \\
\hline 11 & Construction Material Industry & JC & 11 & $0.7 \%$ \\
\hline 12 & The Standardization Institute of & CECS & 11 & $0.7 \%$ \\
\hline 13 & Chinese Construction & YB & 10 & $0.7 \%$ \\
\hline 14 & Metallurgical Industry & Others & 102 & $6.7 \%$ \\
\hline
\end{tabular}

Fig.1 shows the distribution of standards on environmental pollution improvement differentiated by essential attribute. It can be investigated that there are 556 technical standards and 400 method standards which occupy $36.4 \%$ and $26.2 \%$ of the total standard of third-party governance on environmental pollution, separately. As well, there are also 222 management standards, 173 product standards, 122 process standards. Other standards including basic standards, design standards and safety standards only accounts for $11.6 \%$.

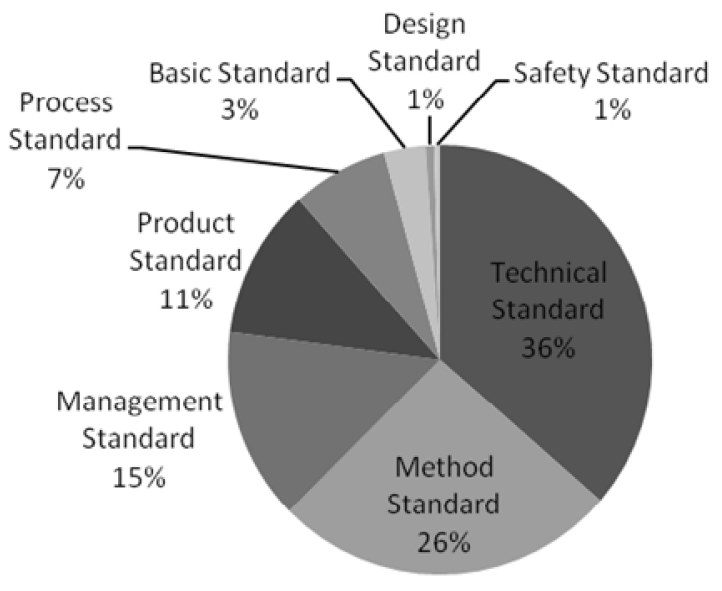

Fig.1 Distribution of standards on environmental pollution improvement differentiated by essential attribute 


\section{Researches on TEPC-supporting standard system}

The framework of TEPC-supported standard system, as shown in Figure 2, is established based on TEPC-related standards from the perspectives of economic management, social responsibility and control effect as well as in combination of standard systems with TEPC-supported generic technology, management and service standards. Specifically, such a framework is composed of four aspects according to main technical contents and project boundaries involved in environmental governance, i.e., general basics, pollution control equipment and technology, pollution control project construction and management, and pollution control performance monitoring and assessment. Based on this, the framework takes main control objects of subsystems as the top priority and standardized classification methods as the basis, focuses on the whole life cycle of pollution control, and attaches importance to structural balance and coordination of standard systems. These four subsystems are further decomposed into 22 aspects so as to establish a three-level standard system framework.

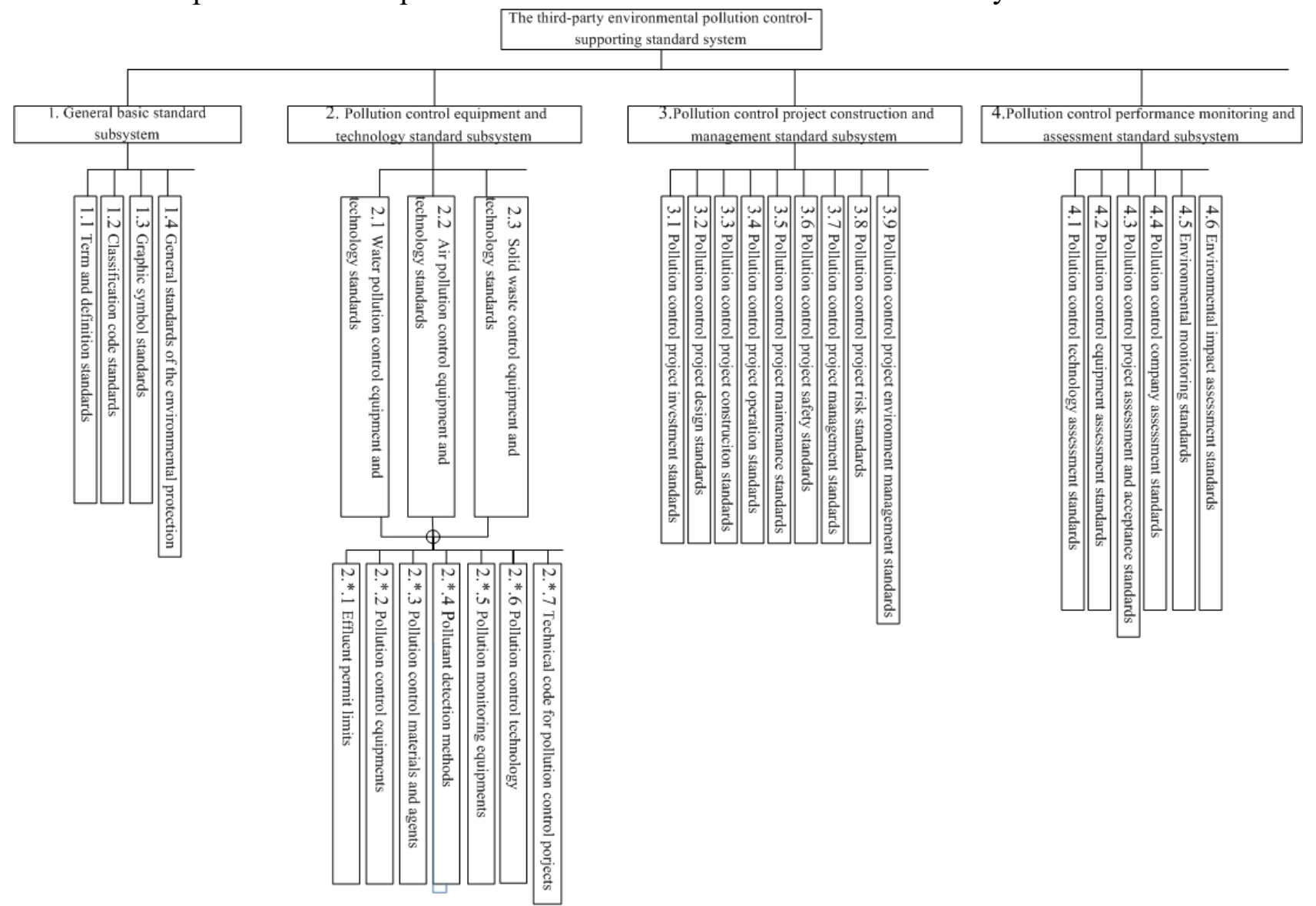

Fig.2 Standardization system structure based on third-party governance on environmental pollution

On this basis, these four subsystems can be subdivided according to their characteristics and coverage. In specific, the general basic standard subsystem is a summary of basic and general standards, and, together with other three standard subsystems, represents the inheritance relationships between common and individual standards as well as the aggregation relationships between the whole and the parts.

The basic standards refer to those with general terms and conditions in a broad scope of application or covering a specific field. The general basic standard subsystem covers the standards for terminologies, definitions, classification codes and labels, graphic symbols and texts, as well as general rules for environmental protection.

The pollution control equipment and technology standard subsystem can be divided into three sub-subsystems, i.e. water pollution control equipment and technology, atmospheric pollution control equipment and technology, and solid waste treatment $\&$ disposal equipment and technology. With respect to atmospheric pollution control, it can be divided into six sub-subsystems according to the 
professional structure of pollution control technology, namely, atmospheric pollutant emission limit, atmospheric pollution control product and equipment, atmospheric pollutant detection method, atmospheric pollution control technology and process requirement, technical specifications for atmospheric pollution control, and eco-friendly material, drugs and components for atmospheric pollution control. With respect to water pollution control, it includes sewage and wastewater treatment as well as sludge disposal and can be divided into 12 sub-subsystems according to the professional structure of pollution control technology, namely, water and sludge pollutant emission limit, water and sludge pollution control product and equipment, water and sludge pollutant detection method, water and sludge pollutant treatment technology and process requirement, technical specifications for water and sludge pollution control, and eco-friendly material, drugs and components for water and sludge pollution control. With respect to solid waste treatment, it includes solid and hazardous waste treatment and disposal and can be divided into 13 sub-subsystems according to the professional structure of pollution control technology, namely, solid and hazardous waste pollutant control limit, product and equipment, solid and hazardous waste detection method, solid waste recovery and treatment technology and process, technical specifications for treatment and disposal of solid waste raw materials and recycled products, and eco-friendly materials and drugs for solid and hazardous waste pollution control.

According to the whole life cycle, environmental pollution control projects cover the stages of investment, design, construction, installation, operation, maintenance, management, etc. Based on this, the standard subsystem of pollution control project construction and management can be subdivided to establish a project construction standard system related with the pollution control projects, involving nine standards for investment cost estimation, engineering design, project construction, operation \& maintenance, safety regulations, decision-making management, risk distribution and environmental management of the pollution control projects.

As environmental pollution control involves pollution control technology and equipment, project construction, operation management and control effect, whose assessment, however, is an important basis for normalizing pollution discharge and treatment enterprises and also a major reference for environmental service contract management assessment, the standard subsystem for performance assessment and environmental monitoring needs to focus on important processes in TEPC to sort out the assessment and acceptance standards. Moreover, for the purpose of assessment of pollution control effects, collection of environmental monitoring data and environmental impact assessment in the whole project should be taken into consideration. Therefore, the standard subsystem for pollution control performance assessment and environmental monitoring can be subdivided into six types of standards: technical assessment; equipment operation effect assessment; project acceptance assessment; service effect assessment of pollution control enterprises; environmental monitoring and environmental impact assessment.

\section{Element analysis for TEPC-supporting standard system}

Element analysis for the standard system aims to determine the composition of TEPC standard system and then to analyze its elements according to its professional structure.

\section{Element analysis for general basic standard subsystem}

According to the research results on current standards, it is found that 81 basic standards can be explored by third-party governance on environmental pollution. Among which, there are 25 Chinese national standards including 12 term and definition standards, 10 classification code standards and 3 general standards of the environmental protection.

Large amounts of technical specifications and guidelines for environmental engineering, technical guidelines for atmospheric and water pollution control projects and guidelines for preparation of environmental engineering design documents have been formulated and have guiding significance for 
environmental pollution control project regulations. At present, there are no guiding and general TEPC-supported standards for project construction and performance assessment.

\section{Element analysis for the standard subsystem of pollution control equipment and technology}

Standards for atmosphere, water and solid waste emission and control are important bases and premises for TEPC, thus research, formulation and revisions of emission standards are of great significance. By now, there have been 416 current national standards directly related to pollution control equipment and technology, in which national standards for water pollution have the largest percentage.

As shown in Figure 3, there are 677 industry standards on atmospheric, water and solid waste pollution control equipment and technology, in which standards on detection methods are in the majority. The environmental protection industry emphasizes the standards of pollutant emission limit, detection, environmental protection equipment and technology specifications, while the machinery industry emphasizes the standards of sewage treatment and air pollution control equipment. In Figure 3 , Series 1 (blue) represents the distribution of national standards on pollution control equipment and technology while Series 2 (red) represents the distribution of industry standards.

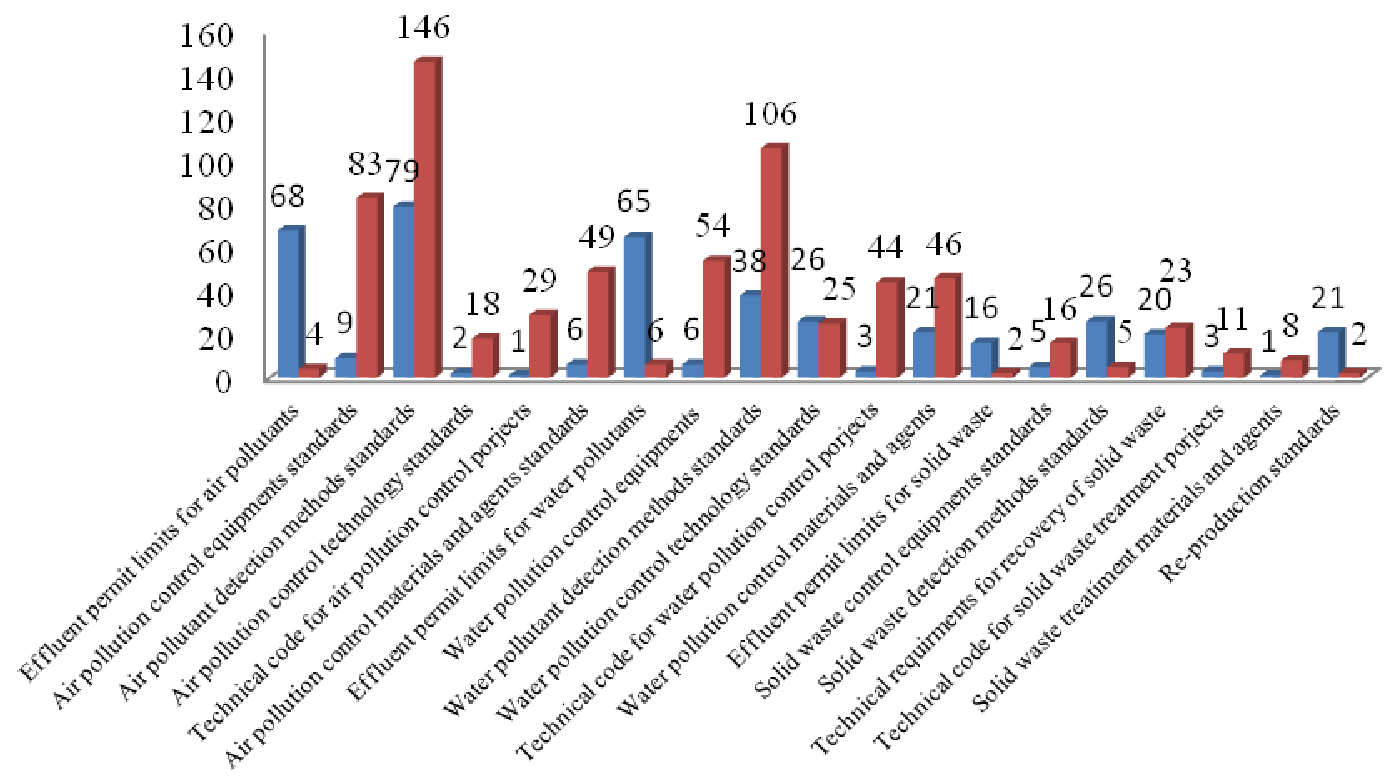

Fig.3 Distribution of standards on pollution control technology and equipment

According to the analysis on the structure and contents of current standards and adaptability of those standards to environmental protection and control industry in China, it can be found that China's standards on pollution control technology and equipment are lack of some key standards. In most respects, industry standards are far more than national standards, but in emission limit as well as raw and recycled materials of solid wastes, national standards are far more than industry standards. However, there are still such problems as serious crossing and repetition between some national and industry standards and poor practicability. In addition, there are a smaller number of national standards on technology, process and technical specifications of atmospheric pollution control, technical specifications of solid waste pollution treatment and disposal equipment as well as solid waste pollution control materials.

\section{Element analysis for the standard subsystem of pollution control project construction and management}

At present, there are 239 current standards on pollution control project construction and management in China, including 82 national standards and 157 industry ones, as shown in Figure 4. 
Among those standards, the project design standards account for $50.2 \%$ and the project operation standards $12.1 \%$. There is a lack of national standards for maintenance and investment of pollution control projects.

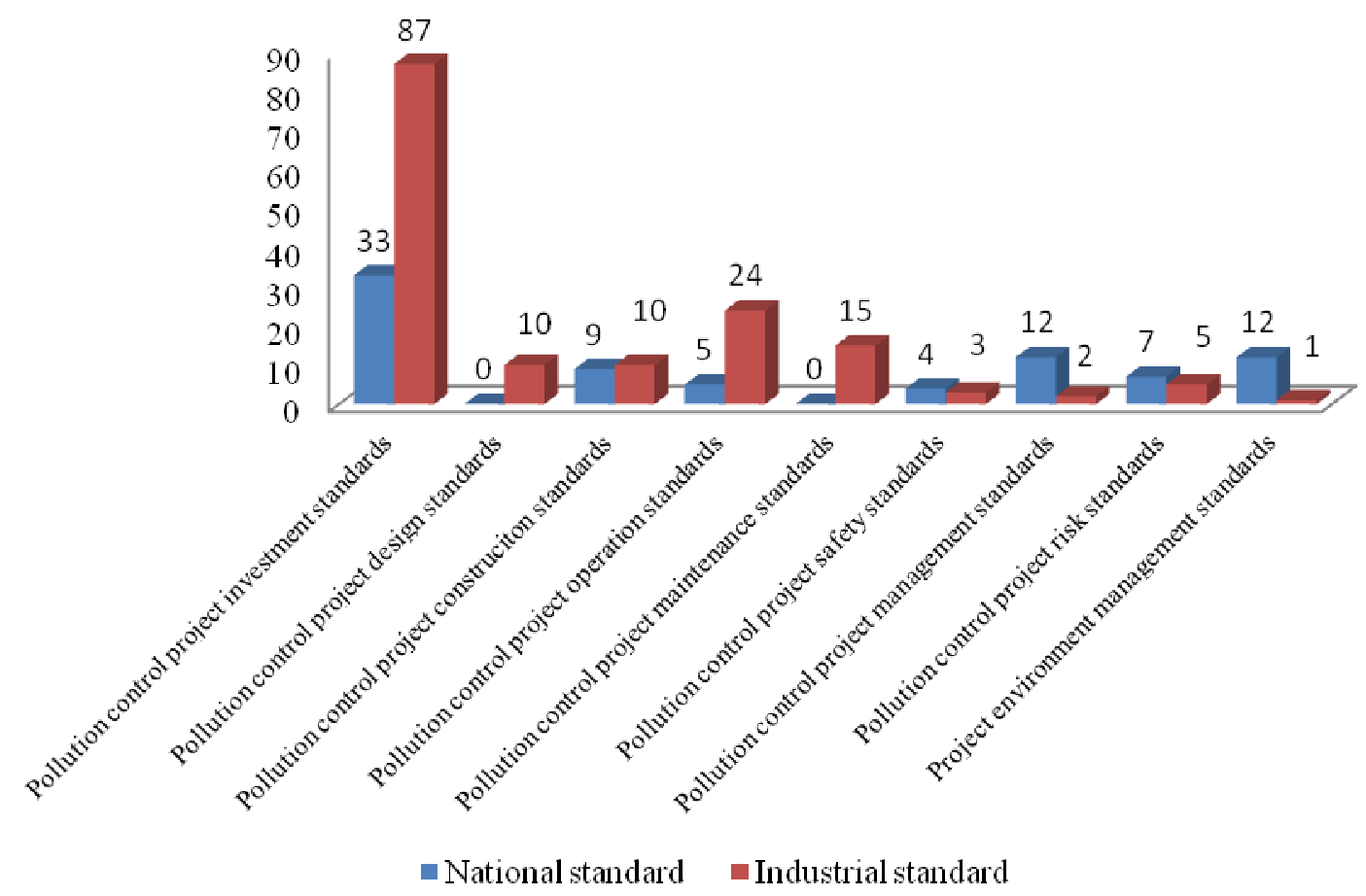

Fig.4 Distribution of standards on pollution control project construction and management

In terms of project design, there are national standards for environmental protection design specifications for key industries, such as iron \& steel industry, textile industry enterprises, and cement and glass factories. Moreover, the fields of steel and non-ferrous metallurgy have been provided with design specifications for acid making with smelting gas, ammonia desulphurization of flue gas from metallurgically sintered pellets, ventilation, de-dusting and fume scrubbing of aluminum smelter, BFG dry bag filters, comprehensive sewage treatment for iron and steel enterprises, and dust collection design of non-ferrous metals plants. As for the industry standards, the chemical industry is provided with 24 technical regulations for process system engineering design and design specifications for environmental protection of chemical construction projects; the machinery industry is provided with standards for design of de-dusting and wastewater treatment equipment; the environmental protection industry is provided with general technical specifications for bag filters. These standards have guiding significance for specification design of de-dusting projects. For the power industry, a series of technical specifications for design of flue gas desulfurization and de-nitration and wastewater treatment in power plants have been issued.

In terms of project investment, there is a lack of standards for investment into environmental pollution control projects. Only the power industry has issued guidelines for classification of construction budget for biomass \& garbage power generation projects. Preparation and review rules for design budgetary estimate, works settlement and investment estimate of construction projects issued by China Engineering Cost Association have certain reference meanings for cost estimation and financial analysis of environmental pollution control projects.

In terms of project construction, there is only one national standard directly related to environmental pollution control, i.e. Code for Construction of Acid-making Equipment Installation Engineering for Smelting Gases, and the others are based on project construction itself. As for industry standards, the construction industry is provided with project construction standards for domestic waste transfer stations, landfill closure and composting; the environment industry is provided with technical specifications for centralized incineration facility construction on hazardous 
waste; the machinery industry is provided with the technical conditions of machinery installation for electrostatic precipitators; and the power industry is provided with guidelines of flue gas bag filter selection for thermal power plants. These specifications and guidelines have guiding significance for construction of dust pollution control projects. The agriculture industry is provided with technology specifications for biogas digester for domestic sewage treatment. The above industry standards are only construction regulations for industries themselves or specific control technologies and fail to support all works of TEPC project construction, so formulation and revisions of national and industry standards should be strengthened. Scientific and reasonable standards and specifications should be formulated according to professional and technical characteristics of key fields when the commonality requirements are raised.

In terms of operation of pollution control projects, only five national standards have been issued, such as Commissioning Specification for Coal-fired Flue Gas Denitration Equipment and Technical Specification of Operation of Environment Protection Facilities for Lead-acid Battery; in terms of industry standards, some specifications for the operation and commissioning of coal-fire flue gas desulfurization and denitration equipment have been issued in the machinery industry; for environment industry, more emphasis has been placed on the formulation of technical specifications for the operation and management of flue gas control facilities in power plants, technical specifications for the operation supervision and management of urban wastewater treatment plants, as well as standards for the operation of dangerous waste central incineration disposal facilities; meanwhile, specific requirements have also been imposed on the technology and testing methods of the operation recorders of pollution control facilities. In terms of electric power industry, specification requirements have been made on the operation technology of denitration system in power plants, wet desulphurization, dedusting and deslagging, operation of bag-type dust collector, and operation of electric-bag composite dust-collector. However, in respect of operation of pollution control projects, standards and specifications are absent from key industries as a whole for the operation of projects related to air, water and solid waste disposal, and therefore, more efforts need to be made to the formulation and conversion of national standards for project operation in order to guarantee the improvement of pollution control effect.

In respect of maintenance of pollution control projects, national standards for the maintenance of air, water and solid waste disposal projects are absent. The procedural industry standards for urban construction industry on household refuse and urban wastewater cover the operation, maintenance and safety technologies and have reference value for TEPC in respect of the disposal of household refuse and treatment of wastewater.

In respect of safety of pollution control projects, China has formulated project construction-based technical specifications for safety protection engineering and national standards for safety technology specifications for urban wastewater regeneration and acid-making using smelting gas, but national and industry standards for special project safety of pollution control in key areas are still seriously absent.

For engineering, safety and environmental management of pollution control projects, no special standards have been issued for environmental protection industry. Investigations and surveys show that efforts in formulation of existing national standards are mainly made for general construction project management specifications, process management guidelines, project risk management and application guides, environmental management requirements and guides. These national standards can be applied to improve the overall level of management and the quality of pollution control projects, and lay a foundation for daily management work of both pollution discharge parties and pollution control parties. 


\section{Element analysis for pollution control performance monitoring and assessment standard subsystem}

By far, China has 42 effective national standards directly related to pollution control performance monitoring and assessment, which account for $36.5 \%$ of the total of this kind and are mostly about pollution control project assessment and acceptance specifications. Figure 5 shows the distribution of standards on performance evaluation of environmental pollution control. For TEPC technology, operation effect and enterprise service assessment, standards are seriously absent, while these standards constitute important preconditions to meet the gradually comprehensive and specialized demand of third-party environment service, establish standard third-party environment service mode, improve industry governance and level of management, and promote integration and technical innovation of environmental protection industry chain. Similarly, the existing 73 industry standards for pollution control performance assessment are mainly about the assessment procedures, monitoring technical specifications, and technical guidances on environment impact assessment in respect of environment monitoring and project acceptance specifications. In addition, operation effect assessment standards for the reliability and economy of equipment have been prepared in electric power and mechanical industries, and the assessment standards targeted at pollution control enterprises such as household refuse transfer stations, incineration plants, composting plants and wastewater treatment plants have been issued in urban construction industry. It remains urgent to solve the problems of absence of key assessment standards.

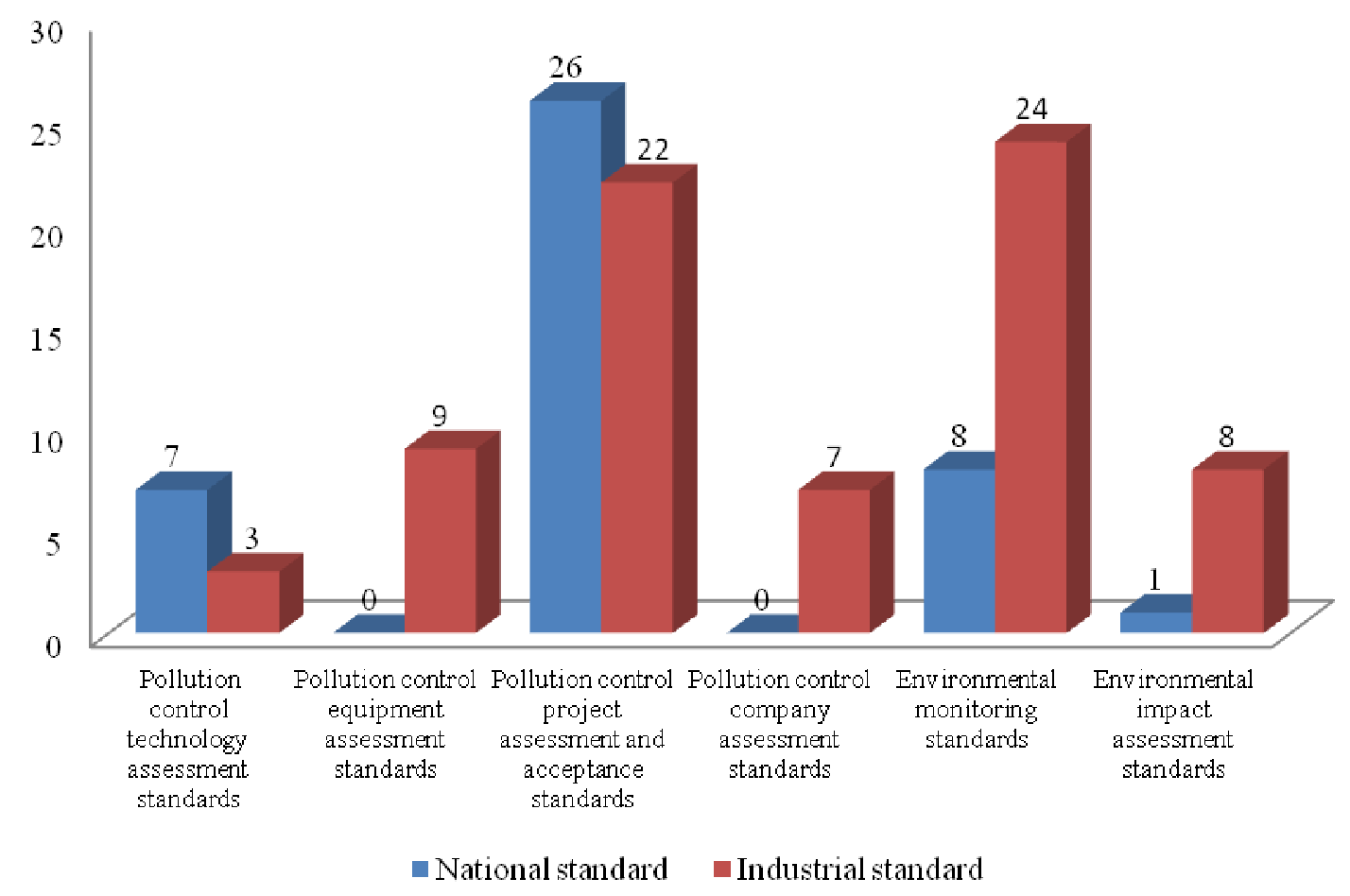

Fig.5 Distribution of standards on performance evaluation of environmental pollution control

As the scope of control services is gradually expanding, the service standards are in increasingly serious shortage. The value of services provided by the environmental protection industry cannot be measured without clear assessment standards. Therefore, formulation of specific specifications and standards, quantifying of front-end and back-end value changes, and calculation of payment price based on the aforesaid will not only help the pollution discharge parties to make clear charging issues but also further promote the standardized development of environmental protection industry at a technical level. 


\section{Conclusions}

At present, the TEPC-supported standards are dispersed in different standard systems based on their related industry type and discipline classification and haven't formed an organic whole. For some standards, lack of early-stage researches results in that the contents of these standards are not scientific or are repeated. And this is adverse to the application and implementation of these standards.

In this paper, a systematic analysis is provided for the basis, principles, composing environment and elements for the establishment of TEPC-supported standard system, a TEPC-supported standard system is set up and a standard list by "traversing" and "keywords" search methods is formulated, and a basic framework of TEPC-supported standard system constructed in terms of of general basics, pollution control equipment and technology, pollution control project construction and management, and pollution control performance monitoring and assessment. When the four areas above are subdivided, they are divided into 22 aspects based on the main working targets of the pollution control covered by the subsystems, further creating a three-level standard system framework.

As for the general basic standard subsystem, emphasis is placed on basic standards for four aspects, i.e. terminologies and definitions, classification symbols and identifications, graphic symbols and texts, and general principles of environmental protection. In the environmental pollution control technology and equipment subsystem, standards are formulated for emission limit, pollution control products and equipment, eco-friendly material, drugs and components for pollution control, pollutant testing method and monitoring equipment, pollution control technology and process requirements, pollution control engineering technical specifications, etc. based on air, water and solid wastes. As for construction and management of pollution control projects, it involves standards for investment, design, construction, operation and maintenance in the process of project construction and focuses on the engineering, risk and environment management of environmental protection projects. In the pollution control performance monitoring and assessment subsystem, emphasis is placed on the classification of standards for pollution control technology assessment, pollution control equipment operation effect assessment, acceptance specifications for pollution control projects, service assessment on pollution control enterprises, as well as environment monitoring and environment impact assessment, which can provide technical support for energy-saving and emission reduction in China.

To sum up, China still has no supporting, formal and complete national standards for performance assessment of third-party environmental protection industry. With economic development and increasing awareness of environmental protection, it becomes more and more important to impose effective synergistic innovation management and make performance assessments in environmental protection industry. Therefore, it is urgent to formulate a complete range of standards for TEPC project performance assessment, which are scientific, reasonable, operable and based on environment service contract management.

\section{Acknowledgements}

This work was financially supported by Central Basic Scientific Research Foundation.

\section{References}

[1] Information on Chinese environmental statistical bulletin, 2015.

[2] X. Wang, Z. Wang and W. T. Yang: Environmental Engineering (in Chinese), Vol.32 (2014), p. $1-5$

[3] J. L. Wang: China Environmental Protection Industry(in Chinese), Vol.11(2015), p.18-21

[4] Z. J. Hua, J. Hua: IEEE, Vol.2(2011), p.730-733 
[5] D. Hao, X. Hou, B. Dong: Environmental Science \& Management, Vol.8(2013), p.1145

[6] Y. Ma: Journal of Environmental Management College of China, Vol.6(2015), p.55-57

[7] B. G. Huang, X. B. Zhao and M. J. Shu: International Journal of Project Management, Vol.31(2013), p.424-433. 